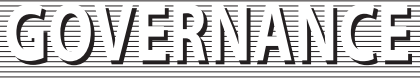

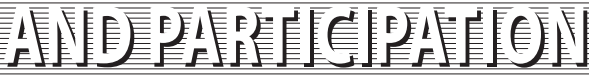

\section{QUANTITATIVE ANALYSIS \\ OF FACTORS AFFECTING CITIZEN \\ PARTICIPATION IN LOCAL GOVERNANCE: THE CASE OF YEREVAN}

\author{
Ruben Hayrapetyan \\ Doctor of Sciences, Professor, Acting Rector \\ at Armenian State University of Economics, \\ Address: 30-19 Davitashen, 3rd district, 0054 Yerevan, Armenia. \\ E-mail: ruben_hayrapetyan@yahoo.com
}

\begin{abstract}
The purpose of this research was to identify the key factors affecting active citizen participation in local governance and understand the extent to which each of them affects the potential participation. A survey was conducted among 1004 citizens of Yerevan to reveal the main characteristics of those who were for and against active participation, their attitudes towards certain types of participation, as well as the reasons for not participating. The questions included in the questionnaire resulted in an input of both dependent and independent variables (predictors). Raw data were processed through Microsoft Excel and then imported into SPSS 20.0 software. Collected primary source data were used to build a binary logistic regression model. The 0.353 value of Nagelkerke R2, which characterizes the predictive power of the logistic regression, may be considered a significant result for analyses in social sciences. The models also revealed individual relationships between potential citizen participation and some specific variables that might enable local authorities to carry out more targeted and effective policies in terms of participatory governance. Disclosure of such relationships can be useful not only for ensuring active participation of citizens in local governance, but also in terms of contribution both to the theory and practice of public administration.
\end{abstract}

Keywords: citizen participation; local governance; binary logistic regression; participatory governance; public administration.

Citation: Hayrapetyan, R. (2019). Quantitative Analysis of Factors Affecting Citizen Participation in Local Governance: The Case of Yerevan. Public Administration Issue, no 6 (Special Issue II, electronic edition), pp. 61-76 (in English); DOI: 10.17323/19995431-2019-0-6-61-76. 


\section{Introduction}

Nowadays, citizen participation in decision-making is one of the necessary conditions for effective local governance. Public services at local level have the peculiarity that they directly affect the everyday living problems of the residents, and they immediately experience that impact in their daily lives.

Participation practices in local governance have experienced a particularly rapid development in the mid-twentieth century, with the use of new mechanisms and methods. According to Roberts, "citizen participation is the process by which members of a society (those not holding office or administrative positions in government) share power with public officials in making substantive decisions related to the community" (Roberts, 2009, p. 7). Beierle defines public participation as any formal mechanism that can invite ordinary citizens or their representatives into decision-making (Beierle, 1998, p. 6).

And irrespective of the fact that the importance level of citizen participation has always been fluctuating, it is obvious that at present these processes are considered as indivisible components of the modern local governance system. Citizen participation has also been referred to by Sherry Arnstein, who interprets it the following way: "The idea of citizen participation is a little like eating spinach: no one is against it in principle because it is good for you" (Arnstein, 1969 , p. 216). Fitzgerald et al. argue that as science and technology advances, traditional stakeholders in the policy-making process should work together with citizens to make an impact by exploiting individual and collective intelligence (Fitzgerald et al., 2016, pp. 257-258).

Mohammadi et al. claim that good governance is driven by enhanced people participation. Since, people participation in local issues is the heart of local governance, it is thus the main factor in local development, with both at the national and local governments taking the lead (Mohammadi et al., 2018, p. 1776). Given this universal support for the idea of community involvement, it can be argued that the main debate among theorists, policymakers and governing bodies is not about the necessity of citizen participation, but rather on how to generate the maximum benefit from this process.

Although citizen participation is a simple idea at first glance, Rosener notes that the seemingly simple phenomenon is actually a very complicated and intricate concept and the lack of knowledge about the effectiveness of participation is probably the result of the fact that few people realize its complexity (Rosener, 1979, p. 458). In this aspect, the literature review reveals extensively diverse and distinctive approaches to the effectiveness of citizen participation (Berner, 2012, pp. 128-163). Some scholars emphasize also the lack of diversity and inclusion. Well-educated, civically active and politically interested citizens are overrepresented in all forms of citizen participation (Michels, 2017, p. 880). A careful study of literature suggests that there are no authors who oppose the idea of citizen participation or consider it a negative process.

However, in many cases people are simply not aware of the forms or methods of participation, and, in general, about having the opportunity to participate. In this regard, in order to ensure effective participation, it is important 
to first understand the factors that affect citizens' decisions to actively participate, which will allow the authorities to evaluate the participatory governance capacities in their administrative units and increase its effectiveness. An indepth study of incentives for participation in local governance is needed not only to evaluate the phenomenon of participation but also to develop and implement appropriate approaches and mechanisms by the authorities. It is also of utmost importance to find out which factors and variables have the largest impact on citizens' decisions to participate. The effectiveness and expediency of citizen participation also depends on who exactly the participants are and what kind of public group they represent.

\section{Methodology}

A survey was conducted among 1004 of the Yerevan electorate in order to reveal the main characteristics of those who were for and against active participation, their attitude towards certain types of participation, as well as the reasons for not participating. The representative sample size was calculated for 850,000 citizens who have the right to vote, at a $95 \%$ confidence level, with a confidence interval of 3 .

The concept of "active participation" was presented as the practice of joint discussion of budget and development plans with local authorities as well as having a direct impact on their decisions. As a result of the preliminary research, the presumption had been that the relative weight of citizens having active participation from the total population would be very low, so an attempt was made through the survey to find answers to the above mentioned questions. The survey was conducted both in electronic form and by hand to hand distribution of questionnaires.

The survey was organized in a way to ensure that all administrative districts of the city, age groups, income groups and other target groups were covered by the questionnaire. At the same time, the questionnaire was designed to the greatest possible extent in a simplified way so that it could provide a larger number of answers and significant representativeness. In particular, all the questions (with the exception of the question on the number of family members) were closed-ended.

Apart from the main characteristics, we have tried to find out what kind of participation was observed among a very limited number of active participants, as well as the main reasons for not participating. By dint of such an approach, it became possible to identify problems of participatory governance and ways to overcome them.

We applied a set of statistical methods to be able to answer questions like "which factors affect citizens' decisions to participate?", "to what extent certain factors affect their decisions?" or "what's the probability of a citizen with given features to participate?". The econometric analysis was summarized by construction of a regression model, the results obtained by which will enable city authorities to identify the potential groups of active participants and develop targeted policies of participatory governance. 
Collected primary source data were used to build the econometric model. It gave us an opportunity to explain and predict citizen participation in the governance of the city.

The questions included in the questionnaire resulted in an input of both dependent and independent variables (predictors). Raw data were processed through Microsoft Excel (Figure 1) and then imported into SPSS 20.0 software. The main task of the presented model was to explain the decisions of citizens to participate in the governance, or otherwise to reveal the "potential participation", which was considered as dependent variable in the model.

\section{Data Analysis and Key Findings}

A simple linear regression model based on an ordinary least squares method could not be applied because the dependent variable is not continuous and can only take two values. A linear probability model had also been considered with dichotomous dependent variable, but it was rejected because all the independent variables also had to be continuous, which we do not have in our case. Both dependent and independent variables have qualitative features.

\section{Figure 1: Processed Raw Data on Citizen Participation in Yerevan through Microsoft Excel (1004 observations)}

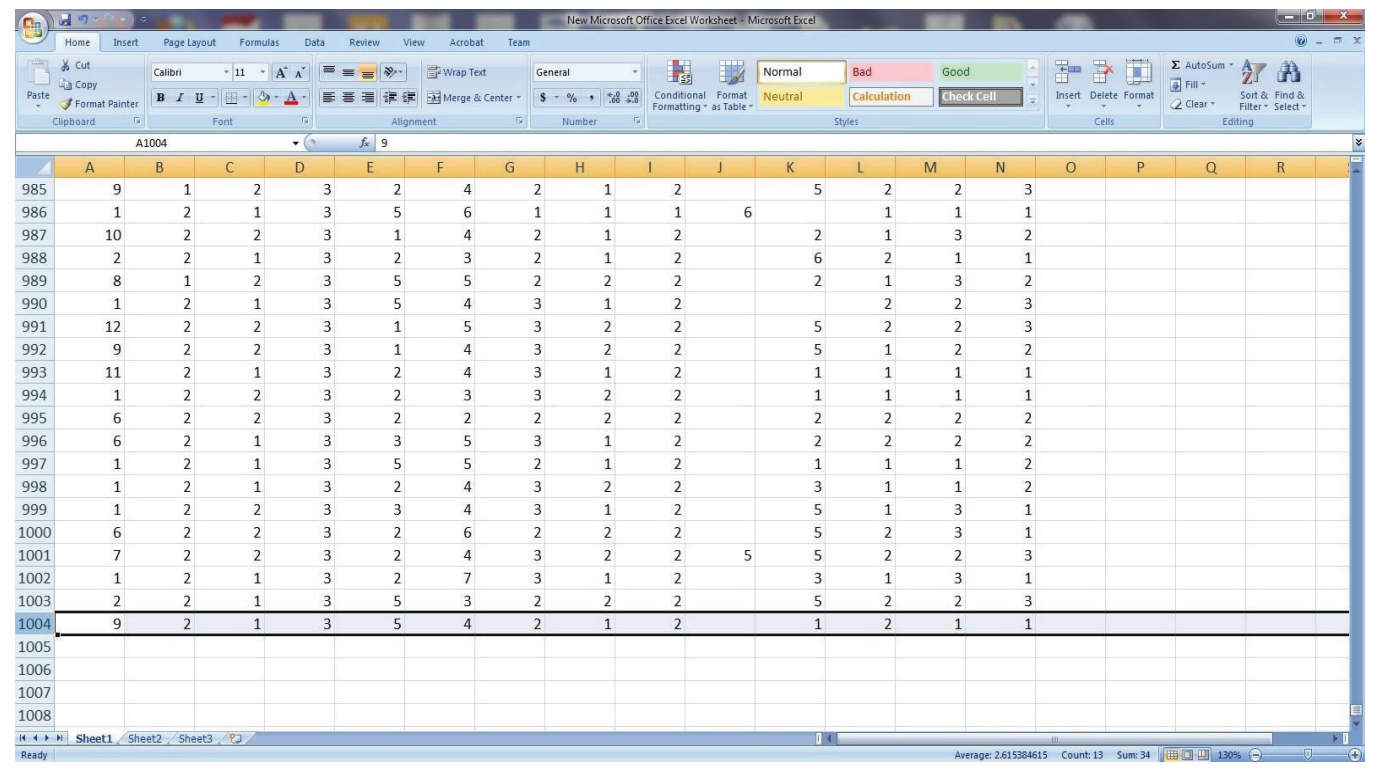

Sources: Compiled by the author according to his own calculations.

For the purpose of analysis of citizen participation in Yerevan, binary logistic regression was applied, which makes it possible to transform qualitative data into quantitative variables through the creation of dummy variables. For each independent variable a specific dummy variable was created, which receives values of either 0 or 1 (Table 1). 
Table 1

\section{Encoding of Dummy Variables Used in the Model}

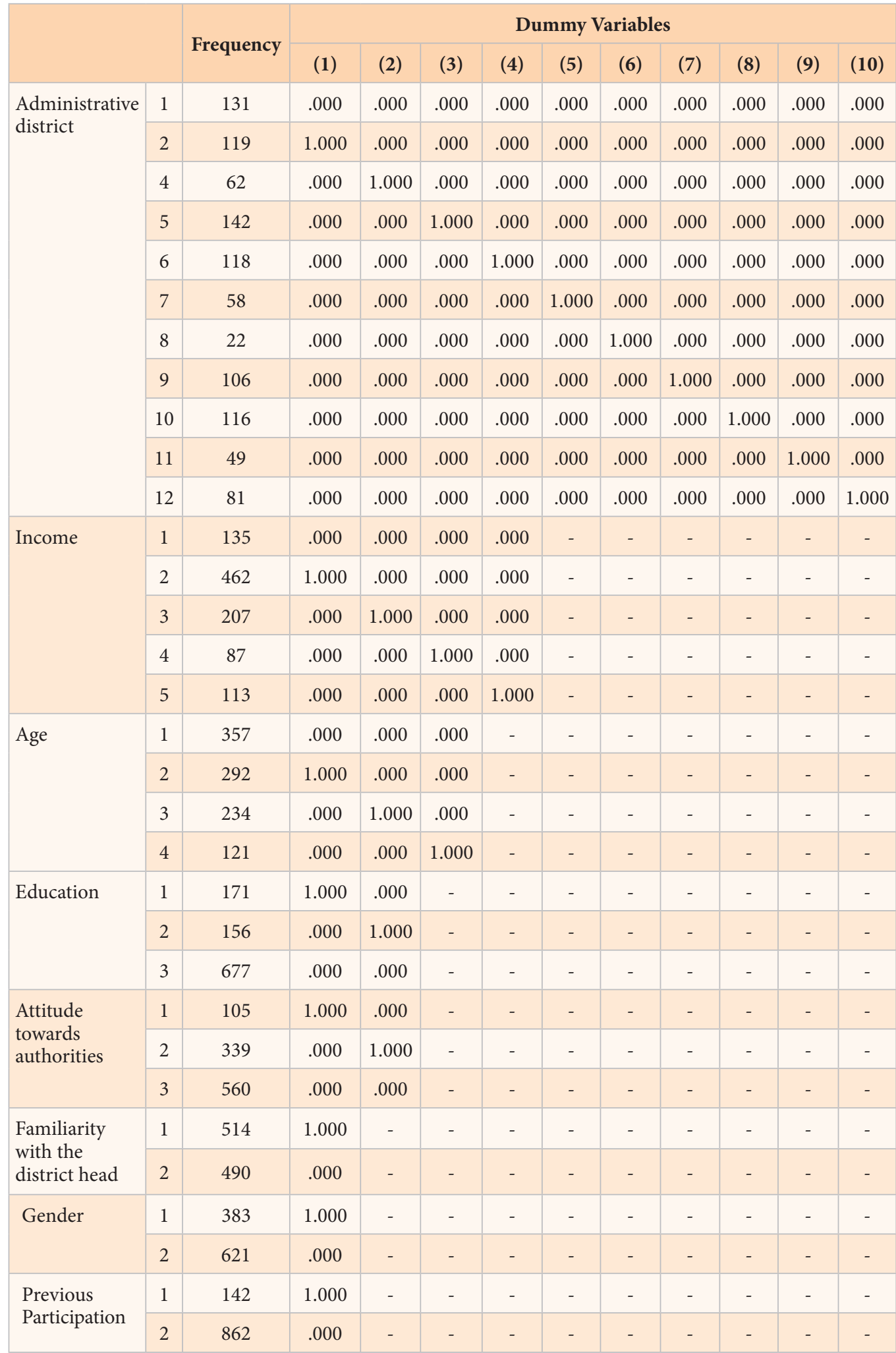


The base model, constructed without the effect of independent variables, predicts the dependent variable to take value " 2 " (which reflects potential participation) with $62.3 \%$ accuracy (Table 2). This is derived from the fact that $62.3 \%$ of the respondents answered "Yes, it's always important" to the following question "Do you think that citizens, including you, should actively participate in the governance of the city?". The other $37.7 \%$ said "no, it's useless". The base model without predictors is worth considering, because by comparing with the main model it's possible to reveal the predicting power of independent variables.

Table 2

\section{Base Model (Without Predictors) Prediction Accuracy}

\begin{tabular}{|c|c|c|c|c|}
\hline & & \multicolumn{3}{|c|}{ Predicted } \\
\hline \multicolumn{2}{|c|}{ Observed } & \multicolumn{2}{|c|}{$\mathbf{Y}$} & \multirow{2}{*}{ Percentage Correct } \\
\hline & & 1 & 2 & \\
\hline \multirow[t]{2}{*}{ Step $0 \mathrm{Y}$} & 1 & 0 & 379 & .0 \\
\hline & 2 & 0 & 625 & 100.0 \\
\hline \multicolumn{4}{|c|}{ Overall Percentage } & 62.3 \\
\hline
\end{tabular}

Table 3 shows dummy variables used for the model, which reflect specific groups of population. For instance, for independent variable "age" 3 dummy variables have been created. The corresponding question in the questionnaire was formulated in the following way: "What is your age?". The options for the answers were: a) 22 and under, b) 23-36, c) 37-52, d) 53 and over. Based on those 4 answers, 3 dummy variables were created and one of them was left out as a reference category (in this particular case, it's first age group, which is used by the model to measure the relative impact of all the other age groups). This kind of approach has been used for the whole model. Dummy variables for three possible answers to the "age" question have been encodes as AG2, AG3 and AG4.

Table 3

\section{Dummy Variables, Used for the Binary Logistic Regression Model}

\begin{tabular}{|l|l|}
\hline \multicolumn{1}{|c|}{ Variable, representing the group } & \multicolumn{1}{c|}{ Description of the Group } \\
\hline AG2 - second age group & $23-36$ \\
\hline AG3 - third age group & $37-52$ \\
\hline AG4 - fourth age group & 53 and over \\
\hline IG2 - second income group & $200-600$ dollars per month \\
\hline IG3 - third income group & $600-1000$ dollars per month \\
\hline IG4 - fourth income group & $1000-1400$ dollars per month \\
\hline IG5 - fifth income group & more than 1400 dollars per month \\
\hline
\end{tabular}


Logistic regression generates values within the range from 0 to 1 , which can be interpreted as probabilities. In the given case the model makes it possible to measure what the probability is for a citizen with specific features (age, income, education, political views, etc.) to be willing to participate in the governance of the city. In fact the model also enables the identification of factors affecting citizen participation.

Hosmer and Lemeshow's goodness-of-fit test, which is based on $\chi^{2}$ (chisquared) distribution, is one of the most robust tests of the logistic regression model, which checks to what extent model fits the specific case. However, unlike other indicators, in this case the model is considered to be fit if the value of probability for identifying statistical significance is more than $5 \%$. In our case (Table 4) the value of $\mathrm{P}$ is 0.876 which is significantly more than 0.05 . This fact allows us to argue that the model largely fits the case and can be applied for predicting potential citizen participation.

Table 4

Hosmer and Lemeshow Test for the Main Model

\begin{tabular}{|c|c|c|c|}
\hline Step & $\chi^{2}$ chi-square & Degrees of Freedom & Statistical Significance (P) \\
\hline 1 & 3.790 & 8 & .876 \\
\hline
\end{tabular}

Because binary logistic regression was used instead of simple or multiple regressions, ordinary $\mathrm{R}^{2}$ is not applicable for measuring the predicting power of the model. For this purpose Nagelkerke $\mathrm{R}^{2}$ was counted instead, which is based on the comparison of the logarithmic values of the probabilities of base and main models (Nagelkerke, 1992).

Table 5

\section{Nagelkerke $\mathrm{R}^{2}$ Coefficient for Measuring Predicting Power of the Main Model}

\begin{tabular}{|c|c|c|}
\hline Step & -2 Log Likelihood & Nagelkerke $\mathbf{R}^{2}$ \\
\hline 1 & 1056.211 & .326 \\
\hline
\end{tabular}

As can be seen from the table, the value of Nagelkerke $\mathrm{R}^{2}$ is 0.326 , which means that potential citizen participation of $32.6 \%$ depends on the value of predicting dummy variables which are included in the model. In accordance with this final fact, it can be asserted that the model is effective for predicting potential citizen participation and has significant level of predicting power.

The main logistic regression model, that includes the impact of independent dummy variables, predicts the dependent variable to take value " 2 " (which reflects potential participation) with $73.6 \%$ accuracy (Table 6). Thus, as compared to the base model (62.3\%), predicting accuracy has increased by $11.3 \%$. This significant growth of model efficiency comes about to reiterate and support 
the positive results, already gained through the Hosmer and Lemeshow test, as well as measuring the Nagelkerke $\mathrm{R}^{2}$ coefficient.

Table 6

Predicting Accuracy of the Main Logistic Regression Model

\begin{tabular}{|c|c|c|c|c|}
\hline & & \multicolumn{3}{|c|}{ Predicted } \\
\hline \multicolumn{2}{|c|}{ Observed } & \multicolumn{2}{|c|}{$\mathbf{Y}$} & \multirow{2}{*}{ Percentage Correct } \\
\hline & & 1 & 2 & \\
\hline \multirow[t]{2}{*}{ Step 1 Y } & 1 & 212 & 167 & 55.9 \\
\hline & 2 & 98 & 527 & 84.3 \\
\hline \multicolumn{4}{|c|}{ Overall Percentage } & 73.6 \\
\hline
\end{tabular}

For the discussion of regression model, it is also important to refer to the statistical significance of the dummy variables and then to exclude from the model those predictors, which do not have $\mathrm{P}<0.05$ value.

Table 7

\section{Variables in the Main Model}

\begin{tabular}{|c|c|c|c|c|c|c|}
\hline & \multirow{2}{*}{$\beta$} & \multirow{2}{*}{ S.E. } & \multirow{2}{*}{ Sig. (P) } & \multirow{2}{*}{$\operatorname{Exp}(\beta)$} & \multicolumn{2}{|c|}{$\begin{array}{c}95.0 \% \text { Confidence Intervals } \\
\text { for } \operatorname{Exp}(\beta)\end{array}$} \\
\hline & & & & & Lower & Upper \\
\hline District & - & - & .428 & - & - & - \\
\hline District1 & -.227 & .312 & .467 & .797 & .433 & 1.469 \\
\hline District2 & -.222 & .376 & .554 & .801 & .383 & 1.673 \\
\hline District3 & .114 & .317 & .718 & 1.121 & .603 & 2.086 \\
\hline District4 & -.221 & .316 & .485 & .802 & .431 & 1.491 \\
\hline District5 & -.400 & .399 & .316 & .670 & .307 & 1.465 \\
\hline District6 & .608 & .562 & .279 & 1.837 & .611 & 5.524 \\
\hline District7 & -.509 & .328 & .121 & .601 & .316 & 1.144 \\
\hline District8 & .181 & .326 & .579 & 1.198 & .633 & 2.268 \\
\hline District9 & .272 & .410 & .507 & 1.313 & .587 & 2.933 \\
\hline District10 & -.147 & .351 & .676 & .864 & .434 & 1.717 \\
\hline Age & - & - & .000 & - & - & - \\
\hline AG2 & -1.073 & .201 & .000 & .342 & .231 & .507 \\
\hline AG3 & -1.631 & .212 & .000 & .196 & .129 & .297 \\
\hline AG4 & -1.316 & .254 & .000 & .268 & .163 & .441 \\
\hline
\end{tabular}




\begin{tabular}{|c|c|c|c|c|c|c|}
\hline & \multirow[t]{2}{*}{$\beta$} & \multirow{2}{*}{ S.E. } & \multirow{2}{*}{ Sig. (P) } & \multirow{2}{*}{$\operatorname{Exp}(\beta)$} & \multicolumn{2}{|c|}{$\begin{array}{l}\text { 95.0\% Confidence Intervals } \\
\text { for } \operatorname{Exp}(\beta)\end{array}$} \\
\hline & & & & & Lower & Upper \\
\hline Male & -.005 & .167 & .978 & .995 & .717 & 1.381 \\
\hline Education & - & - & .000 & - & - & - \\
\hline Secondary & -.982 & .207 & .000 & .375 & .249 & .563 \\
\hline Vocational & -1.022 & .216 & .000 & .360 & .236 & .549 \\
\hline Income & - & - & .002 & - & - & - \\
\hline IG2 & .701 & .232 & .002 & 2.017 & 1.280 & 3.176 \\
\hline IG 3 & .725 & .263 & .006 & 2.065 & 1.233 & 3.458 \\
\hline IG4 & 1.511 & .392 & .000 & 4.529 & 2.102 & 9.761 \\
\hline IG 5 & .786 & .321 & .014 & 2.194 & 1.169 & 4.117 \\
\hline $\begin{array}{l}\text { Attitude towards } \\
\text { authorities }\end{array}$ & - & - & .000 & - & - & - \\
\hline Positive & 2.428 & .458 & .000 & 11.336 & 4.616 & 27.837 \\
\hline Neutral & .407 & .165 & .014 & 1.503 & 1.087 & 2.077 \\
\hline $\begin{array}{l}\text { Familiarity with } \\
\text { the district head }\end{array}$ & .111 & .161 & .492 & 1.117 & .814 & 1.533 \\
\hline $\begin{array}{l}\text { Previous } \\
\text { Participation }\end{array}$ & 1.034 & .285 & .000 & 2.811 & 1.607 & 4.919 \\
\hline Constant & .725 & .344 & .035 & 2.065 & - & - \\
\hline
\end{tabular}

The data included in the fourth column of the table indicate that some of the predicting variables (grayed out) have no statistically significant impact on potential participation $(\mathrm{P}>0.05)$, for example, the group of variables that determine the administrative district. Each of the administrative districts in Yerevan has separate authorities and, in this respect, when modeling the administrative district factor, it was assumed that the respective authorities may have an impact on the decision of the citizens. For this purpose, the corresponding dummy variables have been created for administrative districts, from which "Kentron" administrative district has been adopted as a reference category. However, as the indicators of statistical significance suggest, the potential participation of the population does not depend on the particular administrative district, or in other words the active participation of the residents of Yerevan is equally possible in all administrative districts and there is no significant difference among them.

The results of the analysis show that there are no significant gender-dependent differences in the willingness of the citizens to actively participate. The probability of the null hypothesis to be confirmed is very high, close to $100 \%(\mathrm{P}=0.978)$. The same circumstance is also confirmed by the exponential value of the "Male" dummy variable $(\operatorname{Exp}(\beta)=0.995)$, which means that male citizens are only $0.05 \%$ 
more eager to actively participate in the city administration. Thus, the gender of the participants, as a separate predictor, is not statistically significant and must be excluded from the model.

The same applies to the dummy variable that is created to describe whether the active participation of the population in the governance of Yerevan depends on the factor of recognizing the head of his own district. The latter was incorporated in the model since the elimination of district municipalities in Yerevan and the formation of administrative districts had some negative consequences in terms of the "accessibility" of local authorities. In particular, the current heads of administrative districts, appointed by the mayor (unlike the former heads of municipalities who used to be elected by the population), often detach themselves from the problems of the citizens and lose the connection with them, which is one of the mandatory preconditions of effective local governance.

The survey reveals that 490 out of 1004 citizens of Yerevan, effectively half, do not even know who the head of their administrative district is. This is a very low percentage, given the fact that after the constitutional amendments the main purpose of the formation of the administrative districts was to bring the governance of a major city closer to the population and to ensure the link between the city administration and its citizens through the head of administrative district. Anyway, the results of logistic regression analysis make it clear that this particular factor does not have a significant impact on the willingness of citizens to participate in the decision-making $(\mathrm{P}=0.492>0.05)$. For this reason, the corresponding dummy variables were excluded from the model.

The new improved model was tested both for fitness and predicting power, which produced differing results from the main model. The Hosmer and Lemeshow test results also indicate this time that the probability of null hypothesis confirmation (0.266) significantly exceeds the normative value of 0.05 , which allows us to claim that the improved model also fits the case and it can be used for describing potential participation (Table 8).

Table 8

Hosmer and Lemeshow Test for the Improved Model

\begin{tabular}{|c|c|c|c|}
\hline Step & $\chi^{2}$ chi-square & Degrees of Freedom & Statistical Significance (P) \\
\hline 1 & 11.691 & 8 & .266 \\
\hline
\end{tabular}

As for the predicting power of the improved model, it can be clearly seen in Table 9 that the Nagelkerke $\mathrm{R}^{2}$ value has slightly decreased from its initial value $(0.326)$ to 0.313 , which means that potential participation is by $31.3 \%$ dependent to the changes in the predictors, as included in the model. This insignificant change is a result of the exclusion of statistically non-significant variables from the improved model. Regardless of this fact, the high value of Nagelkerke $R^{2}$ asserts that the improved model is also an effective tool for prediction and has significant predicting power. 
Table 9

\section{Nagelkerke $\mathbf{R}^{2}$ Coefficient for Measuring Predicting Power of the Improved Model}

\begin{tabular}{|c|c|c|}
\hline Step & -2 Log Likelihood & Nagelkerke $\mathbf{R}^{\mathbf{2}}$ \\
\hline 1 & 1068.308 & .313 \\
\hline
\end{tabular}

The improved logistic regression model, that excludes the impact of statistically non-significant dummy variables, predicts the dependent variable to take value "2" (which reflects potential participation) with $72.9 \%$ accuracy (Table 10).

As compared to the base model (62.3\%), predicting accuracy has significantly increased by $10.6 \%$, even though there has been a slight decrease compared to the main model $(0.7 \%)$.

The latter is a result of dismissing non-significant variables from the model. Thus, it can be argued that the improved model is more effective in terms of predicting potential citizen participation.

Table 10

\section{Predicting Accuracy of the Improved Logistic Regression Model}

\begin{tabular}{|c|c|c|c|c|}
\hline & & \multicolumn{3}{|c|}{ Predicted } \\
\hline \multicolumn{2}{|c|}{ Observed } & \multicolumn{2}{|c|}{$\mathbf{Y}$} & \multirow{2}{*}{ Percentage Correct } \\
\hline & & 1 & 2 & \\
\hline \multirow[t]{2}{*}{ Step 1 Y } & 1 & 206 & 173 & 54.4 \\
\hline & 2 & 99 & 526 & 84.2 \\
\hline \multicolumn{4}{|c|}{ Overall Percentage } & 72.9 \\
\hline
\end{tabular}

The values for the dummy variables, used in the improved model, are presented in Table 11. In particular, beta coefficients, their standard errors, statistical significance, exponential values of the coefficients, as well as confidence intervals are counted. The data included in the fourth column of the table indicate that all the predictors included in the improved model are statistically significant, because for all of them null hypothesis is rejected with the $\mathrm{P}<0.05$ value.

The negative value of beta coefficients indicates that the given dummy variable decreases the probability of active participation, and their corresponding exponential values are less than one. For sure, these values depend on the choice of reference category, because the probabilities for dependent variable are counted in terms of relative values of given dummy variable and the reference category. 
Table 11

\section{Variables in the Improved Model}

\begin{tabular}{|c|c|c|c|c|c|c|}
\hline & \multirow{2}{*}{$\beta$} & \multirow{2}{*}{ S.E. } & \multirow{2}{*}{ Sig. (P) } & \multirow{2}{*}{$\operatorname{Exp}(\beta)$} & \multicolumn{2}{|c|}{$\begin{array}{l}95.0 \% \text { Confidence } \\
\text { Intervals for } \operatorname{Exp}(\beta)\end{array}$} \\
\hline & & & & & Lower & Upper \\
\hline Age & - & - & .000 & - & - & - \\
\hline AG2 & -1.013 & .195 & .000 & .363 & .248 & .532 \\
\hline AG3 & -1.569 & .205 & .000 & .208 & .139 & .311 \\
\hline AG4 & -1.204 & .248 & .000 & .300 & .185 & .488 \\
\hline Education & - & - & .000 & - & - & - \\
\hline Secondary & -.944 & .200 & .000 & .389 & .263 & .576 \\
\hline Vocational & -1.015 & .212 & .000 & .362 & .239 & .548 \\
\hline Income & - & - & .000 & - & - & - \\
\hline IG2 & .707 & .227 & .002 & 2.027 & 1.298 & 3.165 \\
\hline IG3 & .799 & .260 & .002 & 2.223 & 1.336 & 3.699 \\
\hline IG4 & 1.628 & .379 & .000 & 5.095 & 2.422 & 10.720 \\
\hline IG5 & .835 & .307 & .006 & 2.305 & 1.264 & 4.205 \\
\hline $\begin{array}{l}\text { Attitude towards } \\
\text { Authorities }\end{array}$ & - & - & .000 & - & - & - \\
\hline Positive & 2.421 & .455 & .000 & 11.258 & 4.612 & 27.482 \\
\hline Neutral & .379 & .160 & .018 & 1.461 & 1.068 & 1.998 \\
\hline $\begin{array}{l}\text { Previous } \\
\text { Participation }\end{array}$ & 1.063 & .281 & .000 & 2.894 & 1.669 & 5.019 \\
\hline Constant & .600 & .250 & .016 & 1.822 & - & - \\
\hline
\end{tabular}

For the economic interpretation of the data, the exponential values of the beta coefficients are particularly important. Thus we will refer to them one by one through the corresponding dummy variables.

As stated already, five dummy variables were created for independent variable "Age" in accordance with specified age groups, from which AG1 (22 and under) was taken out as a reference category. The exponential values of the beta coefficients of age groups show that active involvement in the management of the city is particularly important for those under the age of 22, as the dummy variables for all other age groups have an exponential beta value of less than one, $0.363,0.208$ and 0.300 . The difference is especially significant between the citizens aged under 22 and 37-52. The latter group is $79.2 \%(1-0.208=0.792)$ less likely to have an active participation in city governance, compared to those aged under 22 . Thus, we can assert that citizens under the age of 22 are the most active group for participation in decision making. 
The dummy variable that identifies higher education has been chosen as a reference category for the independent variable "Education". As the theoretical hypothesis suggests, citizens with higher education are more prone to participatory actions (Verba, 1995). In particular, the findings of presented logistic regression suggest that citizens with higher education are much more likely to have an active participation in comparison with the other two groups, more specifically, $61.1 \%$ more compared to those with secondary education, and $63.8 \%$ more than those who have vocational education.

The analysis of income groups provides quite valuable results for potential participation. Five income groups were shaped in the regression model, the first of which was considered as a reference category (up to $\$ 200$ per month). Beta coefficients for other groups have received exponential values of 2.027, 2.223, 5.095 and 2.305, respectively. This data already suggest that participating in local governance is considerably less important for those with less than $200 \$$ monthly, compared to the other groups. However, it is also interesting to note that the representatives of the 4 th income group (\$1000-1400 per month) are particularly active, being more than five times likely to have any willingness for active participation in local governance than the citizens of the first income group. At the same time, it would be a mistake to assert that as the income of the citizens grows, they will tend to have more willingness to participate, because according to the results of the analysis, citizens from the highest income group are about 2.2 times less likely to be willing to actively participate in local governance. Consequently it can be concluded that from the income groups perspective the greatest potential for participation in governance exists among middleincome citizens.

For graphically illustrating the above mentioned dependence, the vertical axis is labeled "potential participation", calculated through the exponential beta values of the income group, and the horizontal axis is labeled "averaged income groups" showing changes in income of the citizens. Figure 2 clearly shows that potential participation of the citizens increases as income grows, however the level of potential participation starts to decline from a certain level of income $(\$ 1200)$.

Figure 2: Potential Citizen Participation, Depending on Income Level

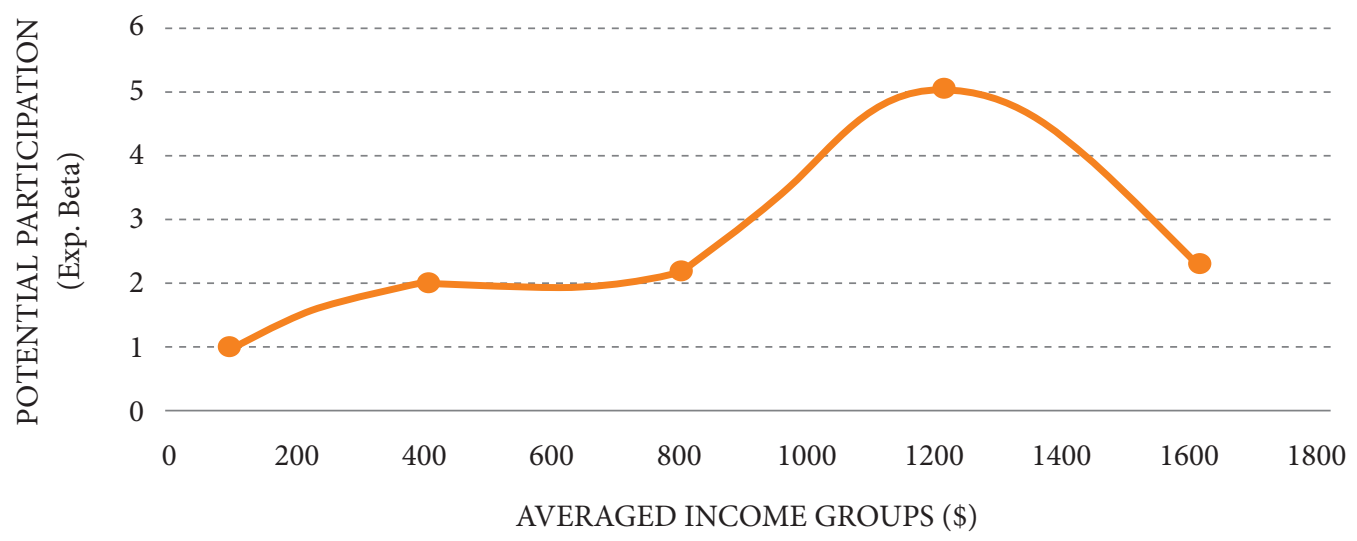


Disclosure of this kind of relationship between income and potential participation can be useful not only for ensuring the active participation of citizens in local governance, but also in terms of contribution both to the theory and practice of public administration. The results obtained in this research consistently prove the need for equitable distribution of income and the formation of a middle class. If there is a high proportion of middle-income people in a given city or country, then a more successful civil society can be formed, with a considerable level of democracy and active civic participation. Citizens with neither high nor low levels of income are as willing to actively participate in decision making at local level as people with middle incomes are. In this sense, a functioning middle class is an indispensable condition for the implementation of effective public administration, based on genuine democracy.

The willingness of citizens to have active participation is significantly affected by their own attitude towards the ruling authorities. Three dummy variables were created based on the predictor "attitude towards authorities" from which "negative attitude" was chosen as a reference category. The results of the analysis show that those citizens who have a positive attitude towards the authorities are 11 times more likely to participate compared to those who have a negative attitude $(\exp (\beta)=11.258)$. It is also important to note that the likelihood of the active participation of neutral citizens is only $46 \%$ higher than those negatively predisposed $(\exp (\beta)=1,461)$. The values obtained prove that the process of participation is largely caused by political factors, which, in fact, hinders effective participation. A considerable part of the population which showed a willingness to actively participate is the segment expressing the will of the city authorities: this circumstance not only impedes effective participatory governance but also suggests that the civic participation mechanisms should be reshaped and improved.

It is logical to assume that the portion of the respondents who had previously been engaged in any type of participatory processes (public hearings, participation in the council meetings, etc.) would be more likely to participate in the future as compared to the rest of the citizens, as they effectively represent the "active community". This hypothesis was also confirmed by a logistic regression analysis, but the exponential value of the corresponding beta coefficient was only 2.894, which means that the likelihood of the active participation of citizens with previous experience of participation was only 2.9 times higher than for the opposite segment of the population. This low exponential beta value of the dummy variable obviously indicates that the existing forms of participation in Yerevan are ineffective and a large number of citizens refuse to participate in the future, being dissatisfied with the outcome of their previous participation experience.

The type of model used in this paper (logistic regression) basically contains two risks that can often have a negative impact on the reliability of the results. The first is the danger of autocorrelation, which, however, relates to models made up of time series data and does not threaten the model we represent. The next risk is the presence of potential multicollinearity, which means that the independent variables are in strong correlation among each other. This is likely to result in high values of standard errors and, thus, underestimate 
or overestimate the impact of individual independent variables on the dependent variable (Baum, 2006). This risk actually threatened the model we presented, so we tried to estimate it by analyzing the correlation between predicting variables (see: Table 12).

Table 12

\section{Correlation Matrix for Dummy Variables, Used in the Improved Model}

\begin{tabular}{|c|c|c|c|c|c|c|c|c|c|c|c|c|}
\hline & AG2 & AG3 & AG4 & $\begin{array}{l}\text { Sec. } \\
\text { Ed. }\end{array}$ & $\begin{array}{l}\text { Voc. } \\
\text { Ed. }\end{array}$ & IG2 & IG3 & IG4 & IG5 & $\begin{array}{l}\text { Pos. } \\
\text { Att. }\end{array}$ & $\begin{array}{l}\text { Neut. } \\
\text { Att. }\end{array}$ & $\begin{array}{l}\text { Prev. } \\
\text { Exp. }\end{array}$ \\
\hline AG2 & 1.00 & .502 & .412 & .186 & .043 & -.039 & -.016 & -.003 & -.015 & -.027 & .050 & -.046 \\
\hline AG3 & .502 & 1.00 & .400 & .092 & -.067 & -.006 & .009 & -.014 & .010 & -.063 & .048 & -.015 \\
\hline AG4 & .412 & .400 & 1.00 & .069 & -.092 & .026 & .045 & -.018 & .037 & -.010 & .041 & -.020 \\
\hline Sec. Ed. & .186 & .092 & .069 & 1.00 & .240 & -.012 & .075 & .054 & .033 & -.029 & -.064 & -.042 \\
\hline Voc. Ed. & .043 & -.067 & -.092 & .240 & 1.00 & .060 & .134 & .125 & .168 & -.039 & -.072 & -.039 \\
\hline $\mathrm{IG} 2$ & -.039 & -.006 & .026 & -.012 & .060 & 1.00 & .684 & .466 & .582 & .027 & -.079 & -.017 \\
\hline IG3 & -.016 & .009 & .045 & .075 & .134 & .684 & 1.00 & .422 & .527 & .045 & -.047 & -.076 \\
\hline IG4 & -.003 & -.014 & -.018 & .054 & .125 & .466 & .422 & 1.00 & .361 & -.006 & -.047 & -.055 \\
\hline IG5 & -.015 & .010 & .037 & .033 & .168 & .582 & .527 & .361 & 1.00 & .025 & -.030 & -.044 \\
\hline Pos. Att. & -.027 & -.063 & -.010 & -.029 & -.039 & .027 & .045 & -.006 & .025 & 1.00 & .122 & -.097 \\
\hline Neut. Att. & .050 & .048 & .041 & -.064 & -.072 & -.079 & -.047 & -.047 & -.030 & .122 & 1.00 & -.002 \\
\hline Prev. Exp. & -.046 & -.015 & -.020 & -.042 & -.039 & -.017 & -.076 & -.055 & -.044 & -.097 & -.002 & 1.00 \\
\hline
\end{tabular}

The data presented in the table show that there is no risk of strong correlation among independent variables. Strong correlation is observed only among the dummy variables from the same category (e.g. 0.684 between IG2 and IG3), which is natural for such variables. And since they can never interact with each other, multicollinearity is also not possible.

\section{Conclusions}

The results obtained through this research enable us to identify the key factors affecting active citizen participation in local governance, understand the extent to which each of them affects the potential participation and also predict it. As a definition of active participation, we considered all the forms of participation that involve joint discussions of the budget, development plans, as well as any other type of direct impact on decision making. The first model included all available independent variables, but because of the lack of statistical signifi- 
cance, some of these were excluded, as a result of which the improved model was suggested. The 0.353 value of Nagelkerke $\mathrm{R}^{2}$, which characterizes the predictive power of the logistic regression, may be considered a significant result for analyses in social sciences (Maddala, 2001). The models also revealed individual relationships between potential citizen participation and some specific variables that might enable local authorities to carry out more targeted and effective policies in terms of participatory governance.

\section{REFERENCE}

1. Arnstein, S. (1969). A Ladder of Citizen Participation. Journal of the American Institute of Planners, vol. 35, no 4, pp. 216-224.

2. Baum, C. (2006). An Introduction to Modern Econometrics Using Stata. Stata Press.

3. Beierle, T. (1998). Public Participation in Environmental Decisions: An Evaluation Framework Using Social Goals. Washington, DC: Resources for the Future.

4. Berner, M. (2012). What Constitutes Effective Citizen Participation in Local Government? Views from City Stakeholders. Public Administration Quarterly, vol. 35, no 1, pp. 128-163.

5. Fitzgerald, C., McCarthy, S., Carton, F., O’Connor, Y., Lynch, L. \& Adam, F. (2016) Citizen Participation in Decision-Making: Can One Make a Difference? Journal of Decision Systems, no 25 , sup. 1, pp. 248-260.

6. Maddala, G. (2001). Introduction to Econometrics, Third Edition. John Wiley, Chichester, UK.

7. Michels, A. \& De Graaf, L. (2017) Examining Citizen Participation: Local Participatory Policymaking and Democracy Revisited. Local Government Studies, vol. 43, no 6, pp. 875-881.

8. Mohammadi, S.H., Norazizan, S. \& Nikkhah, H. A. (2018). Conflicting Perceptions on Participation between Citizens and Members of Local Government. Quality \& quantity, vol. 52, no 4, pp. 1761-1778.

9. Nagelkerke, N. (1992). Maximum Likelihood Estimation of Functional Relationships, Pays-Bas. Lecture Notes in Statistics.

10. Roberts, N. (2009). The Age of Direct Citizen Participation. Armonk, NY: M.E. Sharpe.

11. Rosener, J. (1979). Citizen participation: Can we measure its effectiveness? Public Administration Review, vol. 38, no 5, pp. 457-463.

12. Verba, S. (1995). Voice and Equality: Civic Voluntarism in American Politics. Harvard University Press, Cambridge, MA. 